\title{
Giant osteoma of the paranasal sinuses and right orbit diagnosed using CT imaging in a patient with trauma history
}

\author{
Ewa Kurys-Denis', Małgorzata Olga Zamecka', Joanna Kruk-Bachonko', Witold Krupski \\ 1 /l Department of Diagnostic Radiology, Medical University
}

Kurys-Denis E, Zamecka MO, Kruk-BachonkoJ, Krupski W. Giant osteoma of the paranasal sinuses and right orbit diagnosed using CT imaging in a patient with trauma history. J Pre-Clin Clin Res. 2014; 8(1): 48-50.

\section{Abstract}

This report presents a case of giant osteoma of the right frontal and ethmoidal sinus, nasolacrimal duct and orbit in a patient with history of trauma, investigated using the computed tomography technique. The epidemiology, aetiology, diagnostic methods and treatment of the paranasal sinus osteoma have been reported, as well as discussed with the recently published data pertaining to the subject. The advantages of using computed tomography for detailed diagnosis of morphological features of the pathological changes, as well as their precise localization, have also been presented.

\section{Key words}

osteoma, posttraumatic, paranasal sinuses, orbit, computed tomography

\section{INTRODUCTION}

Osteoma is a relatively rare and benign neoplasm of bone origin, characterized by a relatively slow growth rate and restricted in its localization mainly to the head region [1]. Although relatively rare, it is the most frequent benign tumour of the nose and paranasal sinuses, since it is found in $1 \%$ of patients undergoing plain sinus radiographs and in 3\% of CT examinations obtained for sinonasal symptoms. About $80 \%$ of osteomas occur in the frontal sinus, while ethmoid and maxillary sinuses are affected in about $20 \%$ of cases $[2,3,4]$. The orbital localization of osteoma is not commonly observed; however, if it occurs, it might be a continuation of the changes occurring in the paranasal sinuses. There are only a few reported cases of mandibular localization of the osteoma present in the literature.

The beginning of the development of osteoma may be asymptomatic and often constitute incidental radiographic findings. In the advanced stage, it might induce various symptoms depending on its size and localization. Ethmoid osteomas cause clinical symptoms relatively earlier, as the limited anatomical space results in complaining by the patient. Extension of an osteoma to the orbit and/or skull base is unusual, with a varying incidence of $0.9 \%-5.1 \%$ of all orbital tumours. Generally, the most common symptom of paranasal osteomas is pain including headache and facial pain. When osteomas expand into the orbital vault, they displace the orbital contents and give rise to ocular symptoms, such as diplopia, exophthalmos, proptosis and changes in vision. Osteomas localised lower, in ethmoid cells and maxillary sinuses, may present with anosmia, rhinorrhea or secondary sinusitis. Giant osteomas, regarded as lesions measuring over $3 \mathrm{~cm}$, may first present with facial deformity. $[5,6,7]$.

Address for correspondence: Ewa Kurys-Denis, II Department of Diagnostic Radiology, Medical University, ul. Staszica 16, 20-081 Lublin, Poland

Tel.: +48-81-5321084

Fax: $+48-81-5321084$

e-mail: ekurys@hotmail.com

Received: 30 January 2014; accepted: 15 May 2014
Osteomas appear mainly in middle-aged men with a predominance rate in women of 1.6-1.85 [7]. The great majority of osteomas are of unknown cause and would be regarded in many cases as osseous hamartomas. In the past, three theories have been advanced for the aetiology of osteomas: infectious, traumatic and developmental. Osteomas have also been observed to coexist with nasal polyposis, and more recent studies advocate the role of developmental and genetic factors in the pathogenesis of both those pathologies [8]. Finally, genetic factors may also play a role in the development of osteomas, as in the Gardner syndrome, where multiple osteomas involve preferentially the skull and maxillary sinus.

Surgery is the treatment of choice for symptomatic ethmoid osteomas, however, the approach is under discussion and depends on the extension and the occurrence of complications. Traditional surgical approaches such as external frontoethmoidectomy, lateral rhinotomy or osteoplastic flap technique are often replaced nowadays by a less invasive endoscopic transnasal resection $[8,9,10]$.

This report presents the case of giant osteoma of the frontal and ethmoidal sinus, expanding to the superior and medial nasolacrimal ducts and the right orbit, inducing a few, relatively mild symptoms in a patient with trauma history.

\section{CASE REPORT}

A 75-year old man was referred to our department for diagnosis of an enlarging, delicate hypodermis oedema within the right orbit. The patient reported a trauma to this eye which occurred at the age of 15 and caused the right eye to atrophy later in life. On admission to our department, the patient's neurological and ophthalmological examination results were normal and the patient had not complained of chronic paranasal sinusitis. On otolaryngological examination no tenderness was noted on palpation of the paranasal sinuses. Percussion of the frontal sinuses showed a small difference in the tone with a slight dullness on the right side. On the basis of the clinical picture, the diagnosis 
of tumour was supposed and the patient was referred to a CT examination. Spiral computed tomography of the sinuses and orbits was performed in axial slices of $2 \mathrm{~mm}$ with pitch 1.5 before and after the administration of intravenous iodine contrast in the amount of $60 \mathrm{ml}$. CT images taken before the administration of contrast showed polycyclic, homogenous and hyperdense pathological mass of bone density, measured at $6.8 \times 3.7 \times 4.5 \mathrm{~cm}$, almost completely filling the right frontal sinus, ethmoidal sinuses, superior and medial right nasolacrimal ducts and, partially, the right orbit (Fig. 1A, 1B). The mass did not enhance pathologically post-contrast injection. Examination of the central nervous system did not show any pathological changes. Spatial reconstructions permitted an exact assessment of the pathological mass in relation to the neighbouring structures (Fig. 2A, 2B, 3). After the diagnosis of huge osteoma was established, the patient was referred to the Department of Otolaryngology for a surgical resection of the tumour.
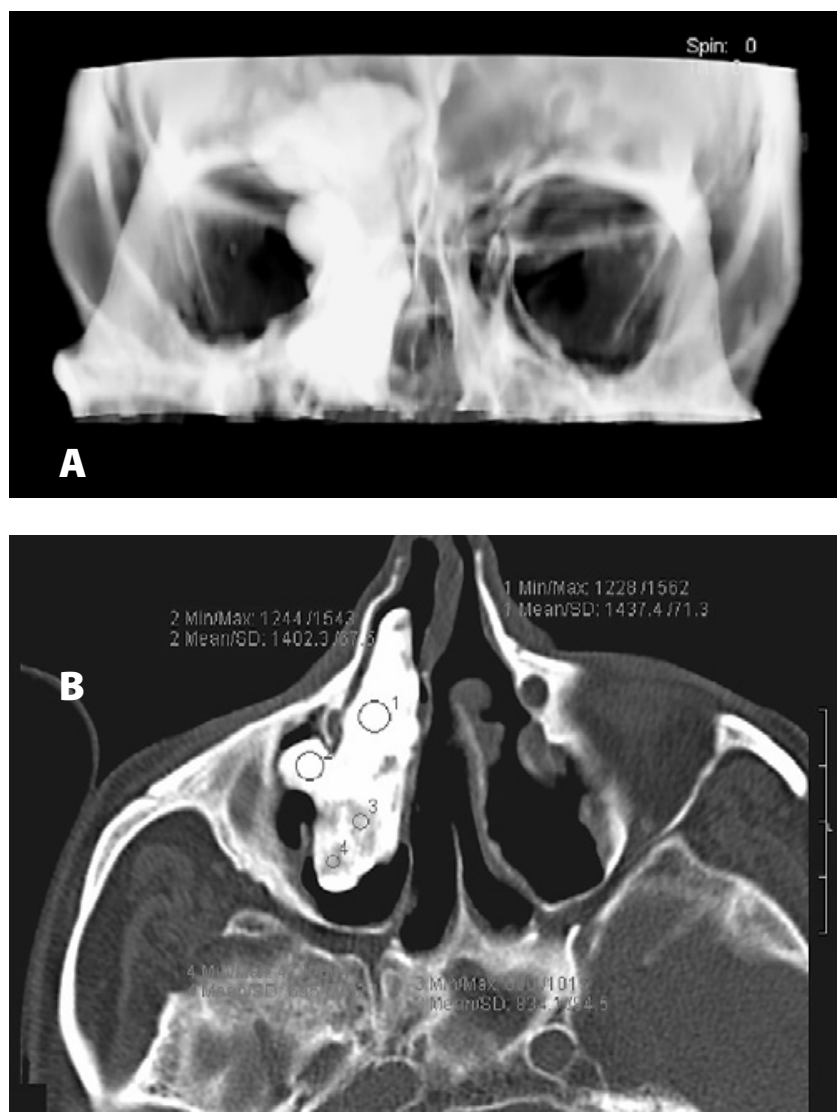

Figure 1 A-B.

A - Irregular shadow of bone density located in the right frontal and ethmoidal sinus, the right orbit and superior and medial nasolacrimal duct.

B - Computed tomography, axial slice: a big, hyperdense mass located in the right medial nasaolacrimal duct

\section{DISCUSSION}

Osteoma belongs to non-malignant tumours of bone origin which usually have a very slow growth rate. It is considered as relatively rare, but its exact incidence is unknown because of the frequent asymptomatic development. As a result of CT investigations of 3,510 of paranasal sinuses, Childrey assessed the osteoma incidence level at $0.43 \%$ [5]. Osteoma is twice more likely to occur in men than in women with an
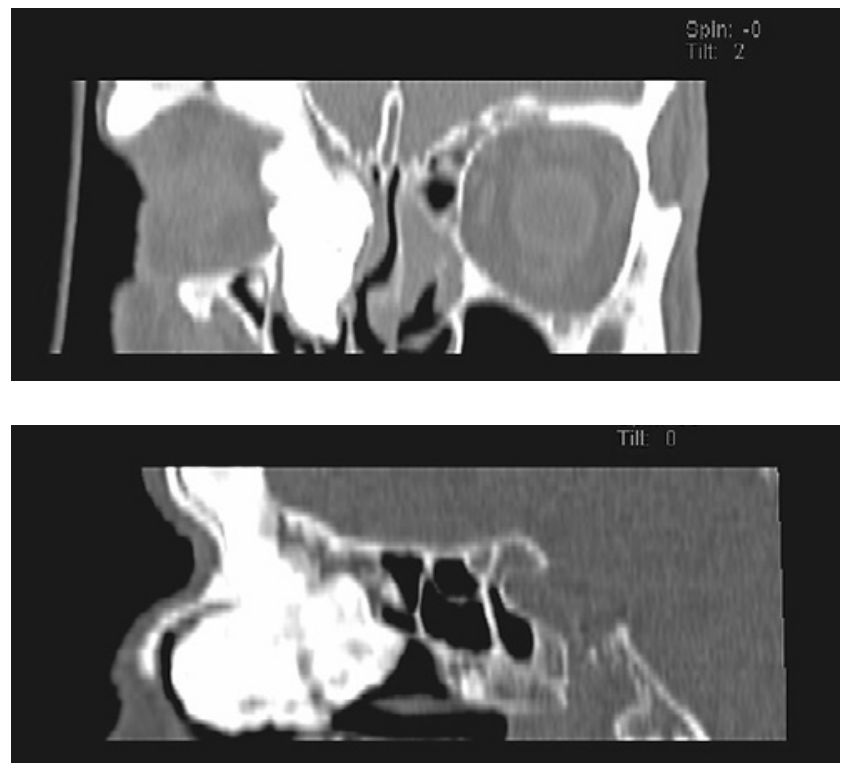

Figure 2 A-B. Osteoma expansion in the right frontal and ethmoidal sinus, superior and medial right nasolacrimal duct, and partially into the right orbit seen on coronal (A) and sagittal (B) CT reconstructions

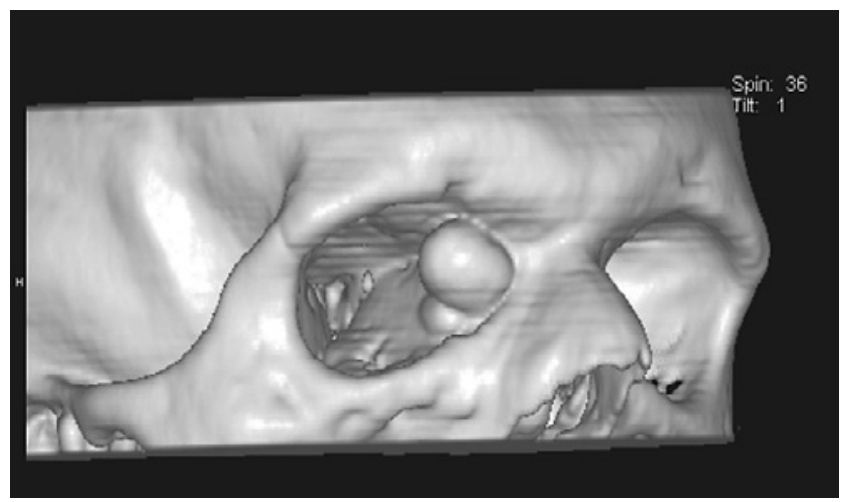

Figure 3. 3D CT reconstruction with bone threshold shows exactly the part of the mass expanding into the right orbit.

exact predominance rate of $1.6-1.85[1,7,11]$. It can develop at any age, even though it is most frequent in the $2^{\text {nd }}$ and $5^{\text {th }}$ decades of life [12]. Osteoma occurs in the following locations within the paranasal sinuses: frontal, ethmoidal, maxillary and sphenoid sinuses (in the order of frequency of occurrence). $80 \%$ of osteomas occur in the frontal sinus, while ethmoid and maxillary sinuses are affected in almost $20 \%$ of cases. Osteoma occurrence in the mandibule is a relatively rare phenomenon; extension of an osteoma to the orbit and/or skull base is unusual, with a varying incidence of $0.9 \%-5.1 \%$ of all orbital tumours; its presence in the long bones is also possible $[13,14]$.

Three theories concerning aetiology of osteoma have been put forward: embryological, traumatic and inflammatory. $[2,11,14]$. The embryological theory claims that places where tissues of different embryological origin come into contact constitute areas of increased risk of neoplastic change development. Within the head area, the bones of frontal and ethmoidal sinuses, the maxillary bone, the smaller brim of the sphenoid bone and the orbital part of the frontal bone belong to locations defined as having such an anatomical structure. 
The traumatic theory was created when a high frequency of head traumas was observed as a factor pre-existing in patients who developed osteomas. This observation led to the assumption that head trauma in pubescence might result in excessive stimulation of bone growth within the trauma localization and, in consequence, cause the development of osteoma. This theory seems to explain the presence of osteoma in the investigated patient, who reported a head trauma at the age of 15. This theory, however, is deemed as having a weakness due to the fact that there is a relatively high incidence of head traumas which are not linked to osteoma occurrence in the population.

Another proposed theory of osteoma origins links the inflammatory processes to the stimulation of osteoblast proliferation. This might be responsible for the formation of the pathological tissue mass and its subsequent development. Similar to the trauma theory, this hypothesis does not fully explain the etiology of pathological changes, the fact that osteoma incidence is much lower in the population than the incidence of paranasal inflammation processes being its main weakness. However, osteomas have often been observed to coexist with nasal polyposis, and more recent studies advocate the role of developmental and genetic factors in the pathogenesis of those both pathologies. [8]. Finally, genetic factors may also play a role in the development of osteomas, as in the Gardner syndrome, where multiple osteomas involve preferentially in the skull and maxillary sinus.

Numerous cases of osteoma, especially relatively small ones, are diagnosed incidentally in patients presenting no symptoms and undergoing radiological head examinations for unrelated reasons. Symptoms caused by the osteoma generally appear in the late stage of the neoplastic development and are closely related to its location. A growing tissue-mass may lead to an obstruction of the sinus ostia and compress the neighbouring structures. In the case of osteoma located in the head, headache can be one of the symptoms. Location in the paranasal sinuses often causes long-lasting sinusitis with underlining localized pain or slight facial asymmetry. Serious intracranial complications in paranasal osteoma have been described very rarely $[15,16]$. Orbit involvement may lead to various visual abnormalities, such as diplopia or proptosis. Relatively few cases of transient single eye blindness and amaurosis fugax have been described $[11,17]$. In the presented case, the only symptom of the giant osteoma was a partial swelling of the orbit's soft tissues. Lack of the typical visual symptoms was a consequence of eye resection on this side in the patient at the age of 15 .

Differential diagnosis of single osteoma involves exclusion of other bone-origin malignant tumours, such as osteosarcoma, osteoid osteoma, osteoblastoma, ossifying fibroma and osteolysing muscle inflammation, and is possible with the use of imaging methods such as computed tomography (CT). On a CT scan, osteoma presents itself as a dense homogenous mass with regular margins; the appearance of this mass does not enhance with contrast administration, neither does it present any bone destruction characteristics. Other malignant lesions are generally non-homogeneous, are variably enhancing with irregular margins, and usually present lytic bone destruction. Osteoma presents expansive, long-lasting growth, and is composed clearly of high density bone structure without soft tissue components that are more characteristic for other lesions, such as osteosarcoma, osteoblastoma, ossifying fibroma or osteolysing muscle inflammation. Osteoid osteoma, on the other hand, is usually a small lesion, rarely bigger that $2 \mathrm{~cm}$ in diameter. The diagnostic value of $3 \mathrm{D}$ and virtual 3D CT, which enable the imaging of a pathological change, as well as precise assessment of neighbouring structures, has already been stressed (18). Furthermore, thin slices of high resolution CT allow for the assessment of the proportion of stable bone tissue to sponge bone tissue and the basis of the osteoma.

Small, asymptomatic osteoma may be scanned every 1-2 years to observe the growth process; in the case of symptomatic occurrences, surgical treatment is necessary, where resecting the whole of the pathologically changed structure, possibly without affecting the neighbouring tissues, is advisable. In osteomas occupying the paranasal sinuses, lateral rhinotomy, external frontoethmoidectomy or osteoplastic flap are usually performed. Prognosis in such tumours is usually good as any recurrence after the complete resection is rare $[13,19]$.

\section{REFERENCES}

1. Atallah N, Jay MM. Osteomas of the paranasal sinuses. J Laryngol Otol 1981; 95: 291-304

2. Eller R, Sillers M. Common fibro-osseous lesions of the paranasal sinuses. Otolaryngol Clin North A. 2006; 39(3): 585-600.

3. Maroldi R, Ravanelli M, Borghesi A et al. Paranasal sinus imaging. Eur J of Radiology 2008; 66: 372-386.

4. Earwaker J. Paranasal sinus osteomas: a review of 46 cases. Skeletal Radiol 1993; 22(6): 417-23.

5. Childrey JH. Osteomas of the sinuses, the frontal and sphenoid bone. Arch Otolaryngol 1939; 30: 63-72.

6. Kyung K. Symptomatic osteoma originated from lamina papyracea. Saudi J of Ophthalmology 2011; 25: 427-429.

7. Mansour AM, Salti H, Uwaydat S, Dakroub R, Bashshour Z. Ethmoid sinus osteoma presenting as epiphora andorbital cellulitos: case report and literature review. Surv Ophtalmol 1999; 43: 413-426.

8. Yiotakis I, Eleftheriadou A, Giotakis E et al. Resection of giant ethmoid osteoma with orbital and skull base extension followed by duraplasty. World J of Surg Oncol. 2008; 6: 110.

9. Wanyura H, Kaminski A, Stopa Z. Treatment of osteomas located between the anterior cranial base and the face. Journal of CranioMaxillofacial Surgery (2005) 33, 267-275.

10. Miłoński J, Pietkiewicz P, Urbaniak J et al. Unilateral pathological lesions of paranasal sinuses removed by endoscopic surgery. Otolaryngologia Polska 2014; 68: 83-88.

11. Gillman GS, Lampe HB, Allen LH. Orbitoethmoid osteoma: case report of an uncommon presentation of an uncommon tumor. Otolaryngol Head Neck Surgery 1997: S218-220.

12. Emel A, Adil O, Ilyas O, Murat B, Ahmet C. Huge aggressive mixed-type osteoma in a young patient. Oral Radiol 2005; 21: 74-77.

13. Lambros Z, Nikolaos L, Papadaki M, Epivatianos A. Osteoma of the ethmoidal sinus: a rare case of recurrence. Brit J Oral Maxillofacial Surgery 2005; 43: 520-522.

14. Moretti A, Croce A, Leone O, D’Agostino L. Osteoma of maxillary sinus: case report. Acta Otorhinolaryngol Ital 2004; 24(4): 219-222.

15.Lori ES, Mascott CR, Tompkins JR, Richardson DE. Frontal sinus osteoma associated with cerebral abscess formation: a case report. Surg Neurol 2001; 55: 235-239.

16. Mehmet K, Umit B, Teoman S, Yucel T, Mahmut S. Huge osteoma of the frontoethmoidal sinus with secondary brain abscess. Auris Nasus Larynx 2000; 27: 285-287.

17. Wilkes SR, Traumann JC, DeSanto LW, Campell RJ. Osteoma: an unusual case of amaurosis fugax. Mayo Clin Proc 1979; 54: 258-260.

18. Fayad, Laura M.; Bluemke, David A.; Fishman, Elliot K. Musculoskeletal Imaging with Computed Tomography and Magnetic Resonance Imaging: When is Computed Tomography the Study of Choice? Current Problems in Diagnostic Radiology 2005; 34: 220-237.

19. Hehar SS, Jones NS. Fronto-ethmoid osteoma: the place of surgery. J Laryngol Otol 1997; 111: 372-375. 